\title{
Kinetic modelling of coking coal fluidity development
}

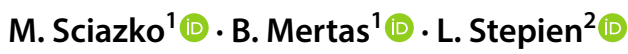

Received: 24 July 2019 / Accepted: 21 February 2020 / Published online: 10 March 2020

(C) The Author(s) 2020

\begin{abstract}
Coal plasticity is a phenomenon directly affecting the creation of coke structure. It is very much a time- and temperaturedependent transformation of the coal matrix, which allows changing the physical phase from solid to liquid-like and again into solid of different properties. The coking process, particularly in a plasticization temperature range, can be considered as a non-isothermal reaction at a constant heating rate. In this work, a macro-kinetics approach is applied that results in effective kinetic parameters, i.e. pre-exponential factor and activation energy. It is postulated in this work that the original content of metaplast $\left(M_{0}\right)$ is a part of volatile matter that melts under the effect of temperature. The coal sample can melt steadily with the temperature increase, achieving the maximum fluidity $\left(F_{\max }\right)$ when the total amount of metaplast available turns into the plastic state. Coal behaviour while it is being heated can be described by two mechanisms. Under first one, the coal turns into plastic phase starting at $t_{1}$ and ending at $t_{\max }$, where solidification starts. This can be considered as independent reactions model. In the second model, both plasticization and solidification reactions compete over entire range of phenomena. This can be considered as reactions in the series model. The developed models were validated against experimental data of coal fluidity delivering kinetic parameters.
\end{abstract}

Keywords Coking coal pyrolysis $\cdot$ Metaplast content $\cdot$ Fluidity development $\cdot$ Phase transition kinetics

\section{Introduction}

When coking coal is heated, it becomes soft in the temperature range $385-450{ }^{\circ} \mathrm{C}$. The temperature range within which the coal forms a plastic mass very much depends on its chemical composition. Upon raising the temperature further, the plastic mass begins to harden, producing solidified, porous coke. The plastic state of coal allows trapping of gaseous products released due to the pyrolysis and allocation of plastic mass into the open interparticle spaces. The volume of the trapped gas depends on coal's properties, particularly on volatile mass released and a plastic mass imperfection caused by the content of insoluble solid particles of coke. The fluidity, on the other hand, is related to its changing viscosity, which is time and temperature dependent. The fluidity measurement is usually measured with a Gieseler

\section{B. Mertas}

bmertas@ichpw.pl

1 Institute for Chemical Processing of Coal, Zamkowa 1, 41-803 Zabrze, Poland

2 AGH University of Science and Technology, al. Mickiewicza 30, 30-059 Kraków, Poland plastometer [1]. In a plastic region, coal particles swell due to the softening and evolution of gaseous components that cause internal pressure to build up in a plastic layer of slot coke-oven charge, eventually generating dangerous wall pressure, also called coking pressure. Uncontrolled increase in this pressure can damage or even destroy oven walls. There are numerous works concerning pyrolysis modelling [2-9], but coal fluidity modelling works are not so often undertaken [10-13]. The main reason is a difficulty in fluidity interpretation in terms of reaction kinetics and its relationship to viscosity, which generally is its reciprocal. In this work, the kinetics of coal transformation into a plastic state and a subsequent solidification are discussed considering two different kinetic models of coal transformation.

\section{Plasticity of coal: the origin of coking pressure}

In a coking oven, two vertical plastic layers are formed parallel to the heating walls, which proceed towards the centre, where they finally coalesce. Released pyrolysis gases move from plasticized coal into porous and cracked semi-coke and coke layers to escape from the coal charge. In a specific temperature range, the plastic layer creates a low-permeability 


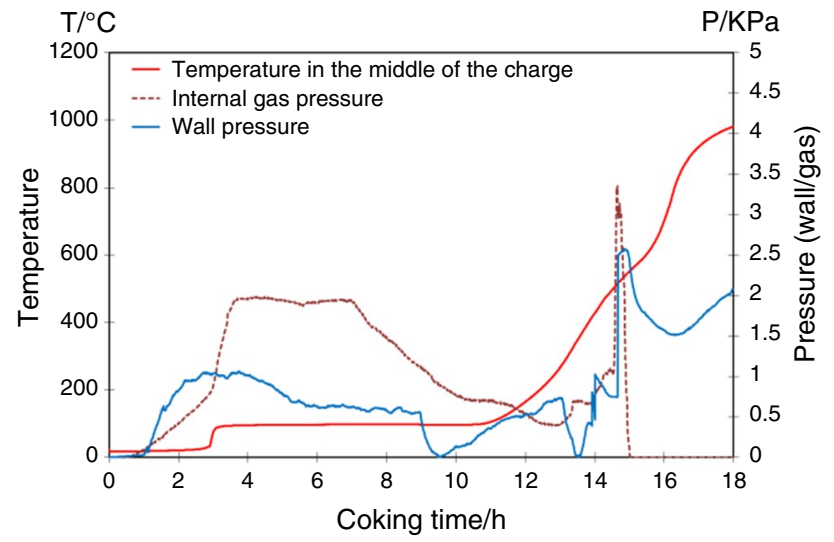

Fig. 1 Coking pressure, internal gas pressure and temperature changes in coal charge [14]

membrane, which prevents the free evacuation of the evolved gas phase from increasing internal pressure. The pressure build-up depends very much on the plasticized coal's viscosity. In the limited space of the oven, there is a maximum pressure build-up in the middle of the coal charge when two plastic layers meet. The internal pressure results in the wall pressure (Fig. 1). This phenomenon occurs in the temperature range of coal plasticity.

Phase changes of the porous coal structure are connected mainly with its chemical properties. Over the last decades, attempts were made to do it based on structural analysis of coal itself as well as its extraction, oxidation, hydrolysis or pyrolysis products $[10,15,16]$. Nevertheless, up until now, a specific single chemical formula was not proposed. This makes difficult the formulation of a specific coal transformation model.

Formation of coke and associated coking pressure are complicated phenomena and can be influenced by several factors, which are presented in Fig. 2. However, the prediction of coke quality is very often based on knowledge of coal fluidity, which is also the most important factor used for the prediction of coking pressure [17-23].

As can be seen, one of the phenomena is temperatureand time-dependent coal softening. What is important is that in the temperature range of coal plasticity, there is an increase in gas devolatilization rate. Figure 3 presents exemplary thermogravimetric (TG) curves of coking coal with volatile matter content $V^{\mathrm{daf}}=21 \%$ (a) and $34 \%$ (b). There are also presented differential thermogravimetry (DTG) and plastic temperature range (according to the Gieseler test). The devolatilization rate rapidly increases when coal starts to solidify. It entails the creation of a resistance to gas transport just in the time of increased amount of gas evolution. The thermogravimetric analysis was performed with TGA501 by LECO. The analysis was conducted at a constant heating rate of $5 \mathrm{~K} \mathrm{~min}^{-1}$, until the final temperature of $900{ }^{\circ} \mathrm{C}$ and under a nitrogen atmosphere.

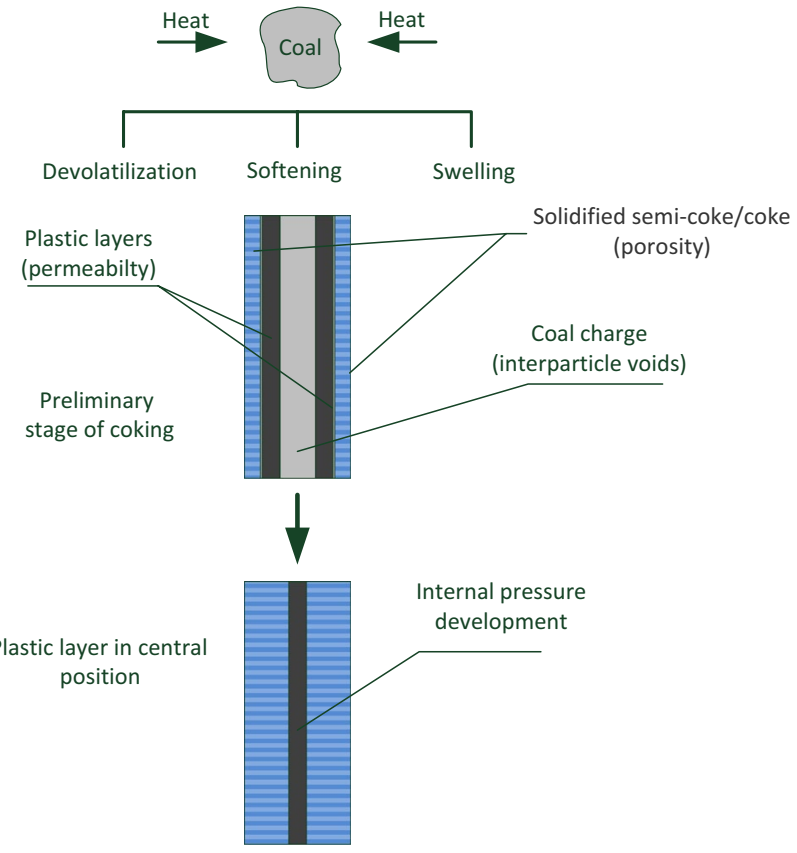

Fig. 2 Stages of coke formation-factors affecting coking pressure

Experimental results indicate that not all macerals of coal particles soften uniformly as Audibert stated [25]. On the other hand, there is no unequivocal proof that the softening part of coal is indigenous or is a pyrolysis product. van Krevelen considered that during heating, a plastic phase called 'metaplast' is created [26]. Swietoslawski [27, 28] states that coking coals contain a material called 'bitumen' and it is in excessive amount that allows coal to soften. Griaznov [29] considered two groups of reactions during plasticizing. In the first one, an unstable structure is created that causes softening and later its solidification. Only coals with the ability to form unstable structure can soften. Ouchi [11] proposed the existence of an indigenous fraction of $\gamma$-components that are low molecular weight and soluble in polar solvents. Regardless of the different softening mechanisms, it can be said that:

- In the coal structure, there are organic softening compounds and inert ones,

- The plastic state occurs within a specific temperature range,

- After passing the softening temperature, an active system is created that entails bonds regrouping and weakening,

- The plastic layer can be considered a colloidal system of inert compound suspended in a plasticized substance, and

- The plastic layer is a system of specific viscosity that causes the formation of a barrier against free gas transport.

The properties of the plastic phase influence the transport of different phases during the coking process. There is difficult transport of released gases if the plastic phase is very 
(a)

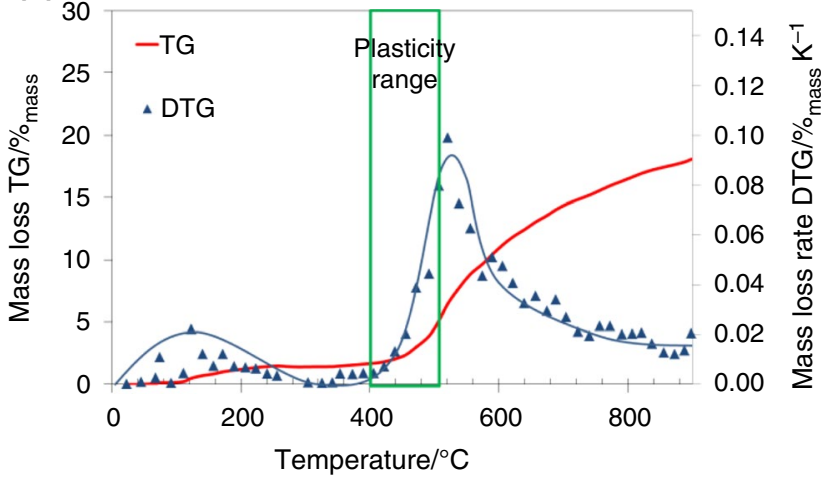

(b)

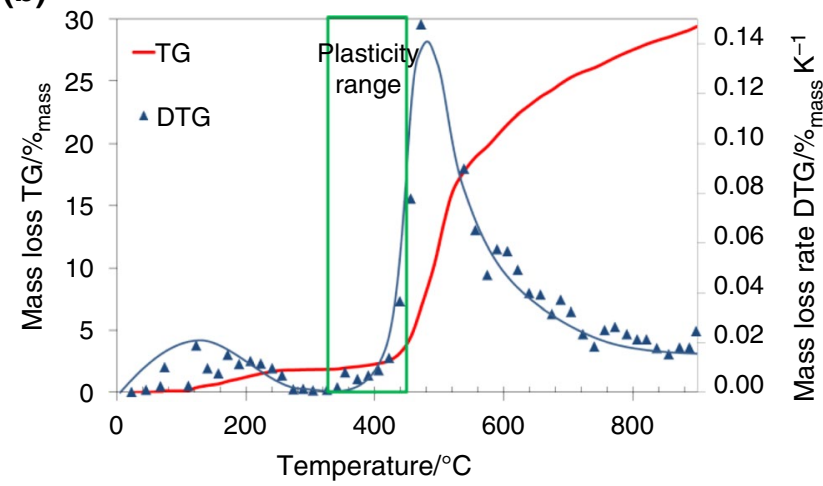

Fig. 3 TG and DTG curves of coking coal with $\mathbf{a} V^{\text {daf }}=21 \%$ and $\mathbf{b} V^{\text {daf }}=34 \%$ [24]

viscous. It may go into empty spaces between particles of non-softened coal or cracked semi-coke if it is very fluid. In the end, it forms the internal structure of the produced coke.

Several works have been conducted on the effect of heating rate. They seem to indicate that for a given coal, the initial generation of liquefied metaplast is independent because the softening temperature $t_{1}$ does not change. However, it does affect the range of plastic behaviour due to the more intensive depolymerization and following solidification. This observation is not useful for the analysis of the coking process, which is conducted at a low heating rate, namely $2-5 \mathrm{~K} \mathrm{~min}^{-1}$.

The most advanced work is [30], in which the multiple independent parallel reaction model was used to describe the isothermal kinetics of plasticity formation due to the metaplast generation and depletion. Using a nonlinear leastsquares regression routine, the activation energy and its variance for each chemical reaction step were fitted to the experimental data. The model requires calculating the mean activation energy and its variance, assuming the same value of pre-exponential factor for all reactions equal to $10^{13} \mathrm{~s}^{-1}$. The mean activation energy was $160-180 \mathrm{~kJ} \mathrm{~mol}^{-1}$ and $250-265 \mathrm{~kJ} \mathrm{~mol}^{-1}$ for melting and solidification reactions, respectively. The data were validated against measured coal viscosity. The authors did not find a relationship between coal rank and kinetic parameters [30].

\section{Metaplast theory}

Assuming the existence of metaplast and following the approach of van Krevelen, the coal devolatilization-pyrolysis can be described by three consecutive steps [26]:

- Depolymerization reaction, in which an unstable intermediate product is formed-metaplast—responsible for the behaviour of coal in a plastic state,
- Cracking reaction, during which non-aromatic groups dissociate, along with parallel recondensation of metaplast, leading to the formation of a semi-coke, and

- Secondary devolatilization reaction, during which the semi-coke structure forms coke along with the simultaneous release of hydrogen, causing the formation of large lamellas.

In line with this theory, the metaplast that is formed and the gas released in this period affect the plasticity and internal pressure development.

\section{Coal samples}

Experimental works were conducted with 15 coals of different origins. Tested coals were from Australia, the USA, Canada, Poland and the Czech Republic. Table 1 presents the ranges of their properties: moisture content $\left(W^{\mathrm{a}}\right)$, ash content $\left(A^{\mathrm{a}}\right)$, volatile matter content $\left(V^{\mathrm{a}}\right)$, fluidity according to the Gieseler test $\left(F_{\max }\right)$, fluidity temperature range according to the Gieseler test $\left(t_{3}-t_{1}\right)$, Sapozhnikov contraction $(x)$, Sapozhnikov plastic layer thickness $(y)$, carbon $\left(C_{\mathrm{t}}^{\mathrm{d}}\right)$, hydrogen $\left(H_{\mathrm{t}}^{\mathrm{d}}\right)$, nitrogen $\left(N^{\mathrm{d}}\right)$ content, vitrinite reflectance $(R)$, swelling index (SI), Movable Wall Oven coking pressure (MWO), Arnu-Audibert contraction (a) and dilatation (b). The most important fact is that the fluidity ranges from a few ddpm up to thousands of ddpm. Table 2 presents the specific coal analysis.

\section{Experimental}

Experimental tests of coal fluidity were carried out with a FRICO Gieseler plastometer. Revolutions were monitored every $1 \mathrm{~min}$. Samples for the test were prepared as a routine sample of size distribution $<0.425 \mathrm{~mm}$ and sample 
Table 1 Coals' properties range

\begin{tabular}{|c|c|c|c|c|c|c|c|c|c|c|c|c|c|}
\hline & $W^{\mathrm{a}} / \%$ & $A^{\mathrm{d}} / \%$ & $V^{\mathrm{d}} / \%$ & $F_{\max } / \mathrm{ddpm}$ & $t_{3}-t_{1} /{ }^{\circ} \mathrm{C}$ & $x / \mathrm{mm}$ & $y / \mathrm{mm}$ & $C_{\mathrm{t}}^{\mathrm{d}} / \%$ & $H_{\mathrm{t}}^{\mathrm{d}} / \%$ & $N^{\mathrm{d}} / \%$ & $R / \%$ & SI & $\mathrm{MWO} / \mathrm{kPa}$ \\
\hline $\min$ & 0.4 & 5.5 & 16.47 & 12 & 53 & 2 & 8 & 77.6 & 4.09 & 1.2 & 0.89 & 7.5 & 1 \\
\hline $\max$ & 1.4 & 10.4 & 32.62 & 29,463 & 116 & 38 & 28 & 86.1 & 5.03 & 2.25 & 1.57 & 9 & 160 \\
\hline
\end{tabular}

Table 2 Investigated coals' specific properties

\begin{tabular}{lllllllrr}
\hline & & $W^{\mathrm{a}} / \%$ & $A^{\mathrm{d}} / \%$ & $V^{\mathrm{d}} / \%$ & $V^{\mathrm{daf}} / \%$ & $a / \%$ & $b / \%$ & $F_{\text {max }} / \mathrm{ddpm}$ \\
\hline AU & 1788 & 0.6 & 5.5 & 25.34 & 26.83 & 22 & 66 & 1032 \\
US & 1789 & 1.0 & 9.0 & 23.40 & 25.72 & 21 & 138 & 1770 \\
AU & 1790 & 1.3 & 7.9 & 32.56 & 35.36 & 20 & 146 & 29,463 \\
AU & 1791 & 1.2 & 9.4 & 20.09 & 22.18 & 18 & 44 & 146 \\
PL & 1792 & 0.7 & 8.8 & 23.77 & 26.05 & 26 & 182 & 3052 \\
AU & 1793 & 0.7 & 7.4 & 22.15 & 23.90 & 20 & 42 & 324 \\
US & 1794 & 1.4 & 7.4 & 32.62 & 35.22 & 22 & 129 & 6074 \\
AU & 1795 & 0.4 & 5.5 & 16.71 & 17.68 & 26 & 34 & 50 \\
AU & 1796 & 0.8 & 10.4 & 16.47 & 18.38 & 18 & 8 & 12 \\
AU & 1797 & 1.2 & 7.7 & 19.59 & 21.22 & 18 & -17 & 14 \\
PL & 1798 & 0.8 & 9.1 & 17.88 & 19.67 & 19 & 17 & 30 \\
PL & 1799 & 1.3 & 7.4 & 30.40 & 32.82 & 20 & 62 & 2154 \\
\hline
\end{tabular}

mass $-5 \mathrm{~g}$. The temperature increase was typical as provided by the standard procedure- $3 \mathrm{~K} \mathrm{~min}^{-1}$. Figure 4 presents examples of fluidity development, which is not symmetric in the scale of temperature. The fluidity increase period is roughly $2 / 3$ and the decrease $1 / 3$ of the temperature range at the condition of the Gieseler test.

A correlation was found between volatile matter content and the maximum fluidity. For the tested coals, it is presented in Fig. 5. It is clearly seen that for coking coals, higher volatile matter content is connected with higher maximum fluidity.

In addition, it was found concerning volatiles' evolution that there exists a relation between total volatile matter content and amount of volatiles in the temperature of fluidity end. Figure 6 presents this. The observed trend can be explained as follows: the coal undergoes pyrolysis and releases the volatiles before achieving the softening temperature in an amount dependent on volatile matter content. High volatile matter content coals lose more volatiles before softening, releasing mostly oxygencontaining species enriching in the same time in hydrogen content, which stabilizes the formed radicals of lower molecular weight. On the other hand, low volatile matter coals when heated release less volatile matter approaching softening temperature and the radicals recombined due to lack of free hydrogen producing lower fluidity of the coal. Despite the differences in fluidity, it is clear that the entire melting phenomenon takes place at an almost constant value of the relative volatile loss, which means that the metaplast $M_{0}$ that forms a liquid-like phase can be assumed equal to $0.8 V^{\text {daf }}$ for all investigated coals.
On the basis of the obtained results, the following relation was proposed (1):

$F(T)=F_{\text {max }} \cdot \frac{M_{\mathrm{F}}(T)}{M_{0}}=\left(a_{1} \cdot V^{\mathrm{daf}}+a_{2}\right) \cdot \frac{M_{\mathrm{F}}(T)}{M_{0}}$

where $a_{1}$ and $a_{2}$ are coefficients derived by regression of the experimental data.

The proposed formula assumes that the ratio of observed fluidity $F(T)$ to maximal value $F_{\max }$ of the sample is proportional to the ratio of observed metaplast content $M(T)$ to its maximal value $M_{0}$.

Experimental data were used to find the best fit with coefficients $a_{1}=0.366$ and $a_{2}=-3.147$. Table 3 presents the correlation coefficient for real and calculated fluidity development as well as mean square error.

\section{Fluidity modelling}

Coal plasticity is a phenomenon directly affecting the creation of coke structure [31, 32]. It is very much a time- and temperature-dependent transformation of the coal matrix, which allows changing the physical phase from solid to liquid and again into solid of different properties. The kinetics of this transformation are complicated considering the detailed coal chemical structure. In this work, a macro-kinetics approach is applied that results in effective kinetic parameters, i.e. pre-exponential factor and activation energy. The coking process, particularly in a plasticization temperature range, can be considered as a non-isothermal reaction at a constant heating rate. 


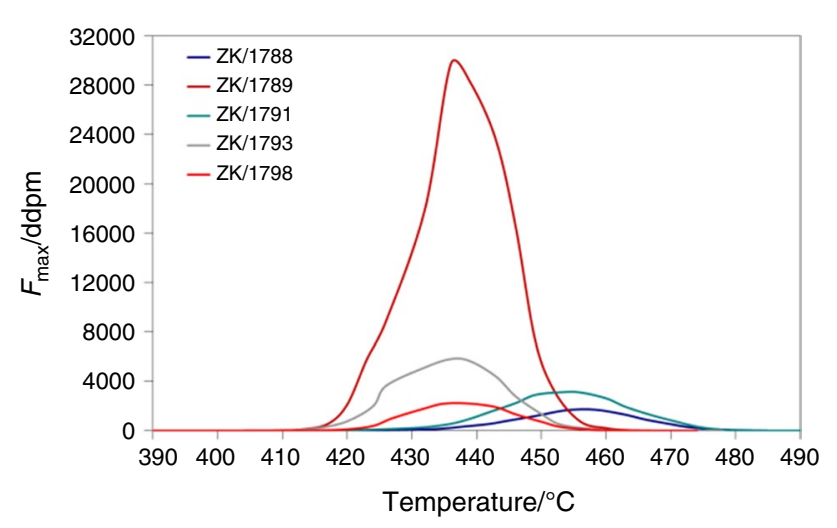

Fig. 4 Fluidity development of selected tested coals

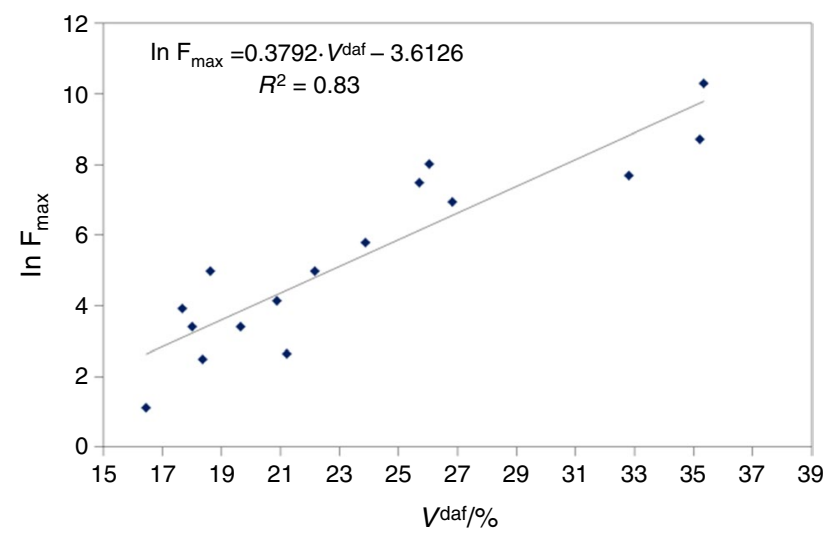

Fig. 5 Maximum fluidity versus volatile matter content

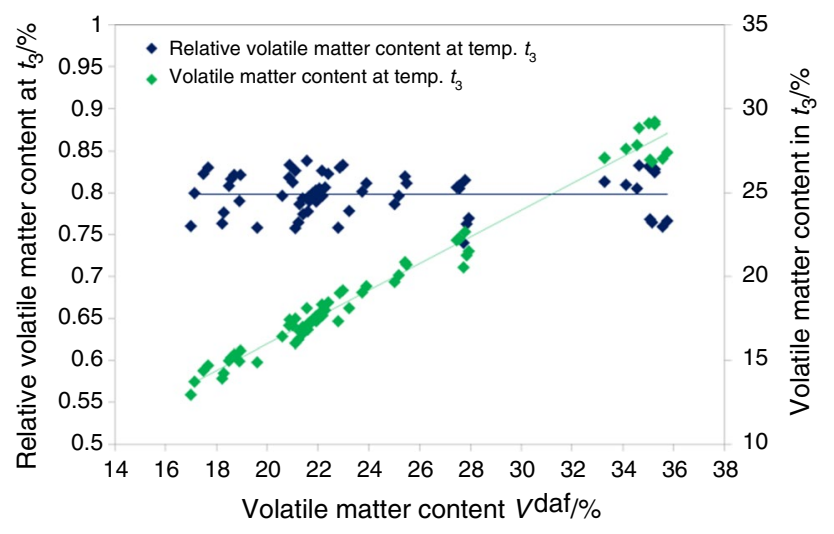

Fig. 6 Volatile content in coal at the time of reaching the temperature of plasticity end versus total content of volatile matter in raw coal
The critical observation, which can be used for the kinetic model solution, is coal fluidity. According to Lloyd et al. [13], it can be assumed that fluidity magnitude is proportional to the share of the plasticizing component in coal. Referring to the concept of van Krevelen [26], the basic reason for coal melting within a certain range of temperature is a content of primary bitumens or $\gamma$-components [11], which, when turned into the plastic state, is called metaplast and accounts for the observed coal fluidity. It is postulated in this work that the original content of metaplast $\left(M_{0}\right)$ is a part of volatile matter that melts under the effect of temperature. The coal sample can melt steadily with the temperature increase, achieving the maximum fluidity $\left(F_{\max }\right)$ when the total amount of metaplast available turns into the plastic state. This takes place at $t_{\max }$ measured by the standard Gieseler test [1]. At temperature greater than $t_{\max }$, a plastic phase starts to turn into solid phase by the initiation of a solidification reaction. Assuming that metaplast properties are very similar for each coal, which discloses plastic properties, and the difference in fluidity can be attributed to the different contents of metaplast, one can derive a general relationship between coal composition and its fluidity. According to metaplast theory, depolymerization of the coal matrix leads to metaplast formation $(P)$, which represents the part of coal that becomes like fluid. It is postulated that metaplast has its origin in the volatile matter content and constitutes a fraction of its content $\left(M_{0}\right)$. The coal fluidity $(F)$ is proportional to the ratio of plastic phase $(P)$ present at the considered temperature to the content of solid phase composed of fixed carbon with ash $(K)$ and still not plasticized metaplast $(M)$ or already solidified plastic phase $(S)$.

This means that the formal mass balance of the sample under consideration in the range of the plastic state can be expressed by the following mass balance equation:

$K+M+P+S=1$

in which metaplast contributes to the three components:

$M_{0}=M+P+S$

The assumption of proportionality allows expressing the fluidity of the sample in terms of the defined components. Fluidity $(F)$ in all mathematical formulae is expressed as the common logarithm:

$F(T)=C \frac{P}{K+S+M}$
Table 3 Correlation results for real and calculated fluidity

\begin{tabular}{lllllllllllll}
\hline Sample & 1788 & 1789 & 1790 & 1791 & 1792 & 1793 & 1794 & 1795 & 1796 & 1797 & 1798 & 1799 \\
\hline$R^{2}$ & 0.90 & 0.96 & 0.99 & 0.79 & 0.98 & 0.94 & 0.86 & 0.32 & 0.02 & 0.81 & 0.92 & 0.94 \\
MSE & 0.56 & 0.21 & 0.02 & 0.88 & 0.05 & 0.43 & 0.18 & 0.43 & 0.90 & 0.19 & 0.37 & 0.07 \\
\hline
\end{tabular}


and, respectively, for maximum fluidity:

$F\left(T_{\max }\right)=C \frac{P_{\max }}{K+M_{\max }+S_{\max }}$

where $C$ in both equations presents proportionality constant.

Taking the above-presented equations, one can derive a fluidity ratio $\Phi$ as:

$\Phi=\frac{F(T)}{F\left(T_{\max }\right)}=\frac{P}{1-P} \frac{1-P_{\max }}{P_{\max }}$

A general scheme of the postulated mechanism is described below. is followed by the solidification reaction. This can be considered the independent reactions model.

- The primary volatile matter is being released, and the remaining amount is equal to $0.8 V^{\text {daf }}$ as metaplast turns into plastic phase starting at $t_{1}$ and at the same temperature starts competitive solidification reaction. This can be considered as reactions in the series model.

Pictorial presentations of both models can be seen in Fig. 7.

\begin{tabular}{|c|c|c|c|}
\hline \multirow{3}{*}{ Coal composition } & \multicolumn{3}{|c|}{$\operatorname{COAL}\left(M_{0}+0.2 V^{\mathrm{daf}}+K\right)$} \\
\hline & \multicolumn{2}{|c|}{ Primary metaplast $\left(M_{0}=0.8 \mathrm{~V}^{\mathrm{daf}}\right)$} & Solid phase $(K)$ \\
\hline & \multicolumn{3}{|c|}{ Metaplast starts to plasticize $\left(t_{1}\right)$. } \\
\hline & $\begin{array}{l}\text { Metaplast fraction in } \\
\text { the plasticized form } \\
\qquad(P>0)\end{array}$ & $\begin{array}{l}\text { Metaplast fraction in } \\
\text { the non-plasticized } \\
\quad \text { form }(S \approx 0)\end{array}$ & $\begin{array}{l}\text { Solid phase } \\
\qquad\left(K+M_{0}\right)\end{array}$ \\
\hline \multirow{2}{*}{$\begin{array}{l}\text { Metaplast plasticizing } \\
\text { Metaplast solidification }\end{array}$} & \multicolumn{3}{|c|}{ Coal maximum fluidity $\left(t_{\max }\right)$} \\
\hline & $\begin{array}{c}\text { Metaplast max. } \\
\text { fraction in the } \\
\text { plasticized form } \\
\left(P_{\max }\right)\end{array}$ & $\begin{array}{l}\text { Metaplast fraction in } \\
\text { the non-plasticized } \\
\text { form }(M)\end{array}$ & Solids $(K+S)$ \\
\hline
\end{tabular}

Metaplast completely solidified $\left(t_{3}\right)$

\begin{tabular}{|c|c|}
\hline $\begin{array}{c}\text { Metaplast is totally } \\
\text { solidified } \\
\left(S=M_{0}\right) .\end{array}$ & $\begin{array}{c}\text { Solids } \\
\left(K+S=K+M_{0}\right)\end{array}$ \\
\hline \multicolumn{2}{|c|}{ Coke } \\
\hline
\end{tabular}

Considering the presented scheme of coal behaviour while it is being heated, the following mechanism can be distinguished:

- The primary volatile matter is being released, and the remaining amount is equal to $0.8 V^{\text {daf }}$ as metaplast turns into plastic phase starting at $t_{1}$ and ending at $t_{\max }$. This

\section{Kinetics of fluidity development: independent reactions (Model A)}

The first kinetic model assumes that the plasticization of coal is related to the metaplast transformation into a fluid-like state. This takes place from $t_{1}$ to $t_{\max }$. Next, the fluid-like phase is transformed into a solid one in the temperature range $t_{\max }$ to $t_{3}$. Both reactions are independent. Such a model can be presented as follows: 
Fig. 7 A scheme presenting the mechanism of a kinetic model

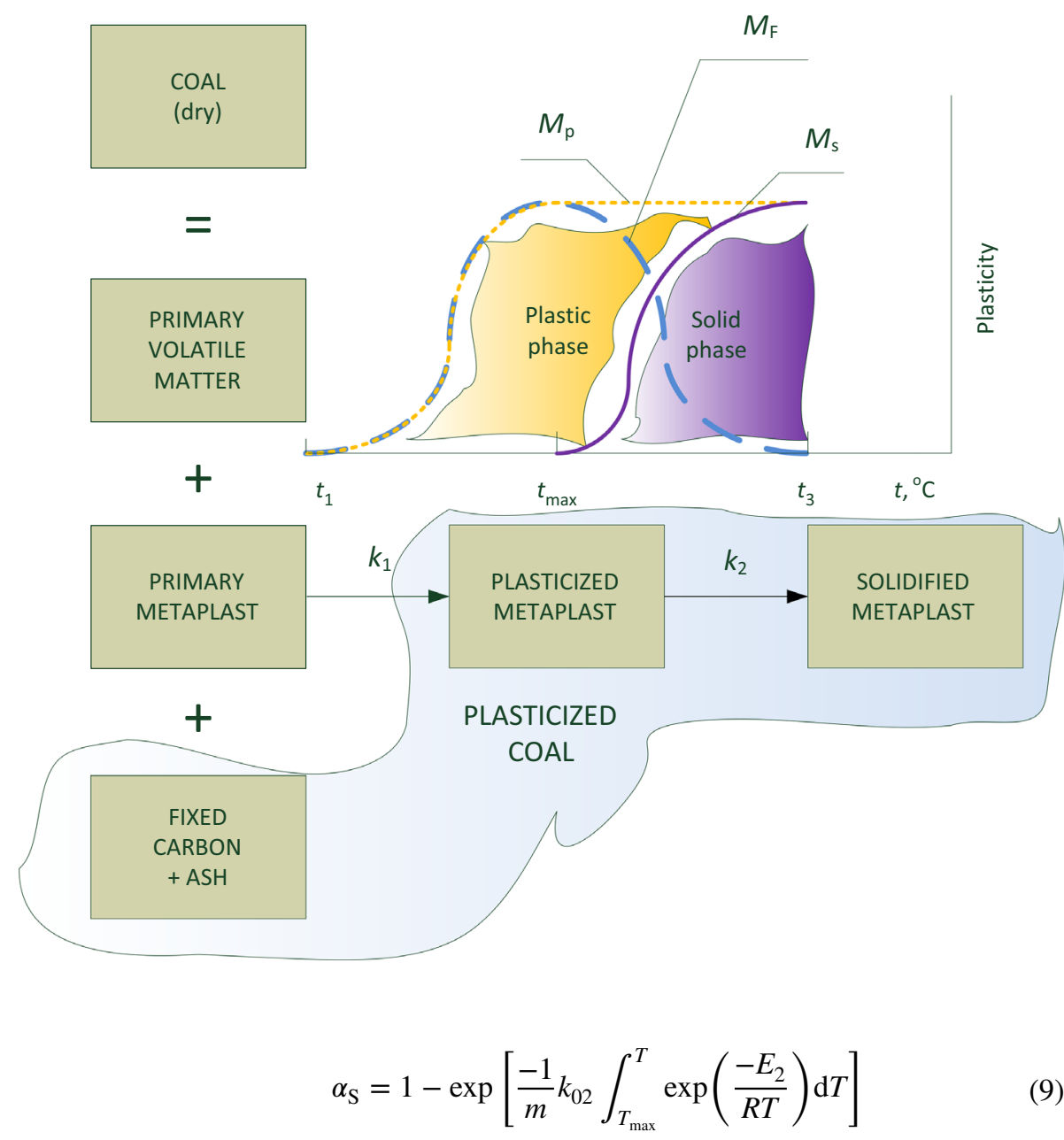

and

$P \stackrel{k 2}{\rightarrow} S$

Using the Levenberg-Marquardt method to minimize the residuals, being the squared difference between experimental $P$ (Eq. 7) and the model one calculated from Eq. 8, the kinetic parameters can be evaluated. The same is repeated for the next region when solidification starts. In this case, the solidified phase fraction is calculated by the difference of $M_{0}$ and $P$. In both cases, fractions of $P$ and $S$ were used that apply the normalization formulae:

$\alpha_{\mathrm{P}}=\frac{P}{M_{0}}$

$\alpha_{\mathrm{S}}=\frac{S}{M_{0}}$

$M_{0}$ equals $0.8 \mathrm{~V}^{\mathrm{daf}}$ as previously presented.

\section{Kinetics of fluidity development: reactions in series (Model B)}

In this case, we consider consecutive first-order reactions such as 
$M \stackrel{k 1 s}{\longrightarrow} P \stackrel{k 2 s}{\longrightarrow} S$

The respective rate equations for the three components and non-isothermal system are:

$r_{\mathrm{M}}=\frac{\mathrm{d} M}{\mathrm{~d} T}=-\frac{1}{m} k_{1 \mathrm{~s}}(T) M$

$r_{\mathrm{P}}=\frac{\mathrm{d} P}{\mathrm{~d} T}=\frac{1}{m} k_{1 \mathrm{~s}}(T) M-k_{2 \mathrm{~s}}(T) P$

$r_{\mathrm{S}}=\frac{\mathrm{d} S}{\mathrm{~d} T}=\frac{1}{m} k_{2 \mathrm{~s}}(T) S$

This set of equations cannot be solved for the non-isothermal case because the variables are not separable. The following steps were taken to find a solution:

- The kinetic constant needs to be assumed as a guess values before the set of equations is solved.

- The equations are solved numerically assuming as starting values $M=M_{0}, P=0$ and $S=0$.

- The maximum of $P$ can be found, which is necessary to calculate plastic phase content along the reaction path according to Eq. (5). In this case, it is not necessary to take the value of $M_{0}$.

- The $P$ calculated and finally $\Phi$ obtained by model calculation need to be compared with the experimental values.

- If the mean standard error of $\Phi$ was less than $1 \%\left(\delta_{1}\right)$, the assumed kinetic parameters are considered correct. In addition, the $t_{\max }$ experimental and calculated was compared, and the results were accepted with the difference not greater than $3 \mathrm{~K}\left(\delta_{2}\right)$.

- Usually, it was not the case, so to find the solution that fulfils the assumed criteria, a factorial design was used. The kinetic parameters found by the trial-and-error approach were used as a starting point. The four factors $\left(E_{1 \mathrm{~s}}, k_{01 \mathrm{~s}}, E_{2 \mathrm{~s}}\right.$ and $\left.k_{02 \mathrm{~s}}\right)$ were taken at two levels, practically in the range of 0.001 for frequency factor and 0.007 and 0.002 for the energy of activation. The $2 \mathrm{k}$ experi- mental runs are based on the $2 \mathrm{k}$ combinations of the \pm 1 factor levels. This results in 16 runs.

- The obtained data were analysed in terms of $\delta_{1}$ and $\delta_{2}$. If the required conditions were met, the results were accepted; if not, the best solution was taken for the next step runs design and calculation. Usually, after two loops, the final results were obtained.

The computation was conducted in the Mathcad environment applying MinErr solver with respect to four kinetic quantities. The course of relative fluidity development was approximated by functions interp and cspline, which allow interpolating real results with a piecewise polynomial function. Computation of the set of differential equations was conducted applying rkfixed solver.

\section{Analysis of results}

A typical course of fluidity $(\ln F)$ is presented in Fig. 8a, b for low and high volatile matter content coals, respectively.

These primary data collected in 12 experimental runs performed for various coals were used for the data normalization according to formulae (7) and then (10) and (11), obtaining conversion fractions for both reactions in a transformed form (Fig. 9a, b).

The first approach to the analysis of the data shows that the temperature of maximum fluidity, $t_{\max }$, follows the changes in primary metaplast content, which is directly referred to the volatile matter content (Fig. 10).

The same can be said about maximum fluidity $(\ln F)$ as presented in Fig. 11.

\section{Kinetic analysis according to Model A}

Kinetic analysis of Model A delivers both activation energy and frequency factor for two specified steps of the reaction. It appears that the frequency factor has a linear relation in the form

$\ln \left(k_{01}\right)=A+B E_{1}$
Fig. 8 The fluidity versus temperature. a Low-volatile coal $1798\left(V^{\text {daf }}=17.68 \%\right)$ and b high-volatile coal 1799 $\left(V^{\mathrm{daf}}=32.82 \%\right)$
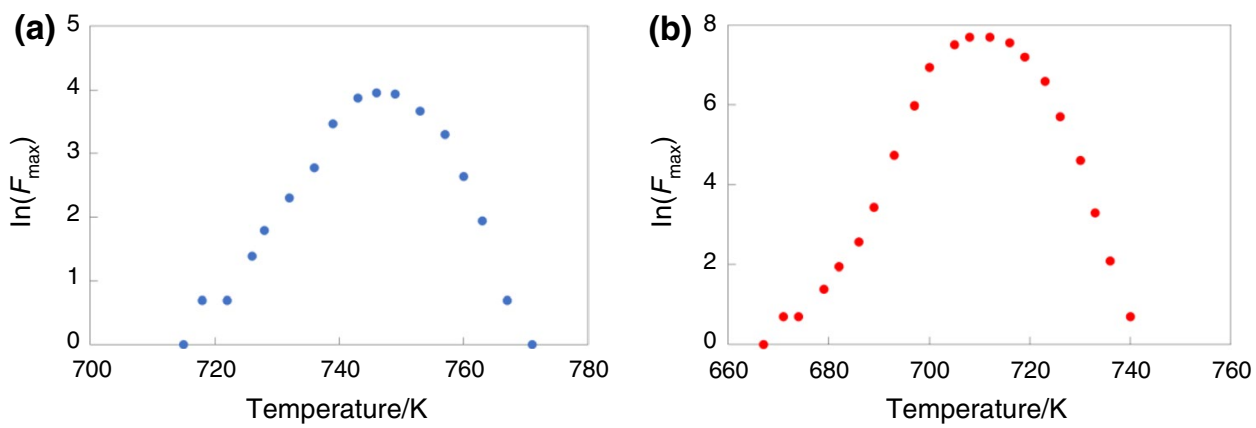
Fig. 9 Normalized fluidity fraction versus temperature. a Low-volatile coal 1798 $\left(V^{\mathrm{daf}}=17.68 \%\right)$ and $\mathbf{b}$ high-volatile coal $1799\left(V^{\text {daf }}=32.82 \%\right)$.
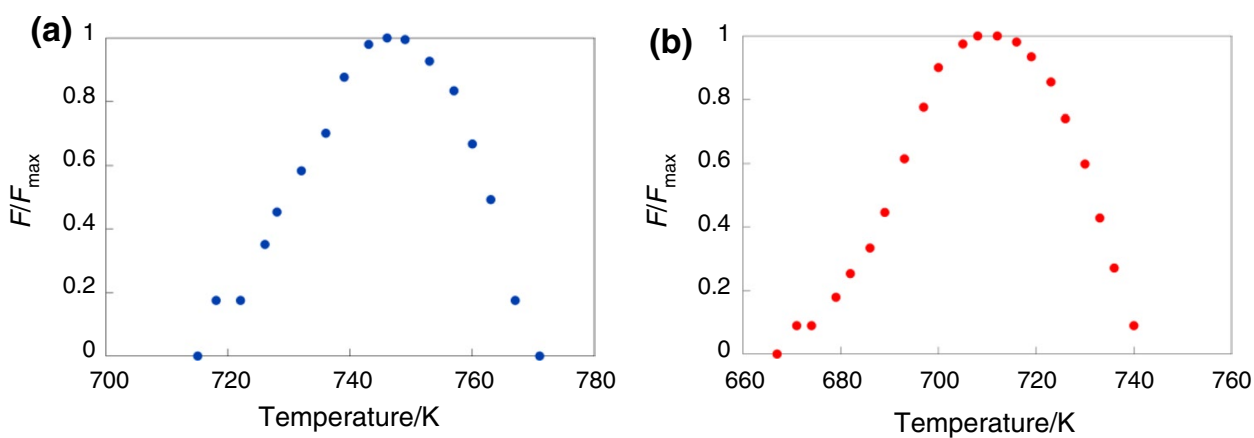

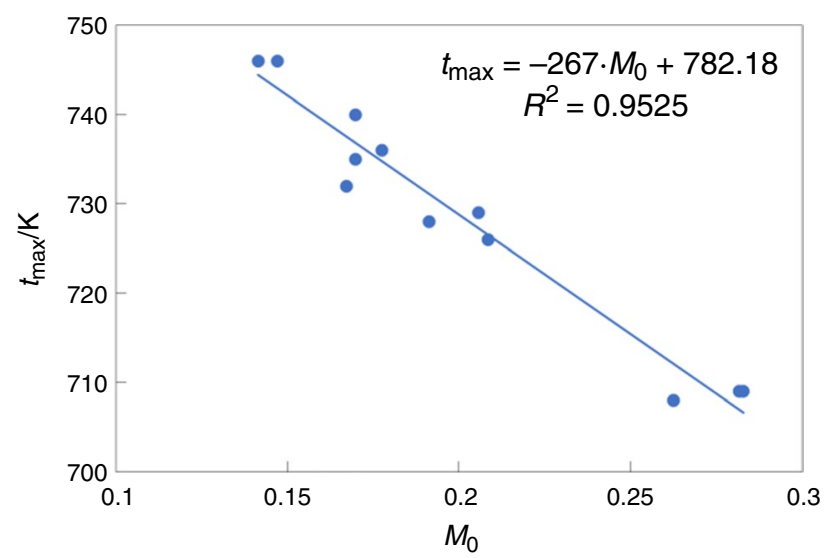

Fig. 10 The temperature of maximum plasticity versus primary metaplast content

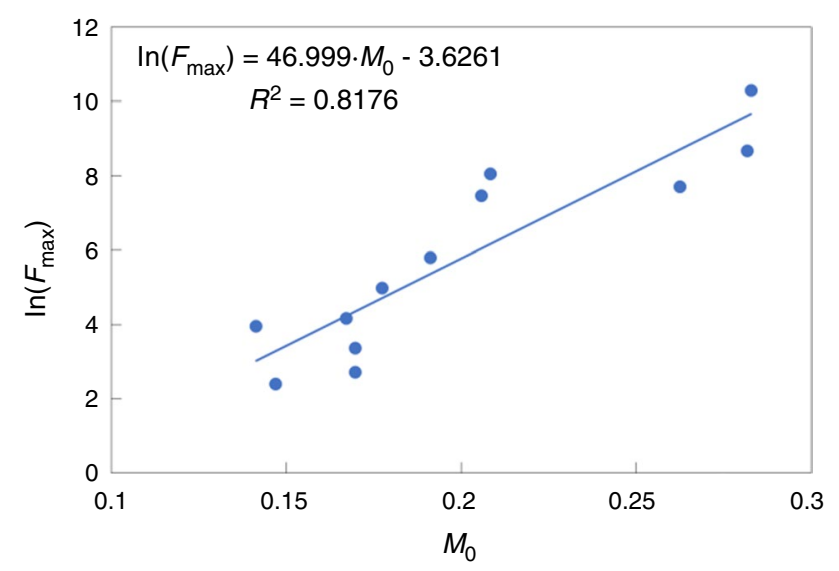

Fig. 11 Maximum fluidity versus metaplast content

This type of relation is called a compensation effect and generally shows that the greater the value of the frequency factor is, the greater the value of the activation energy. The activation energy of the first step is in the range of 200 to $380 \mathrm{~kJ} \mathrm{~mol}^{-1}$, which can be considered already a rather high value. The values for the solidification step are much higher approaching almost $1000 \mathrm{~kJ} \mathrm{~mol}^{-1}$. The

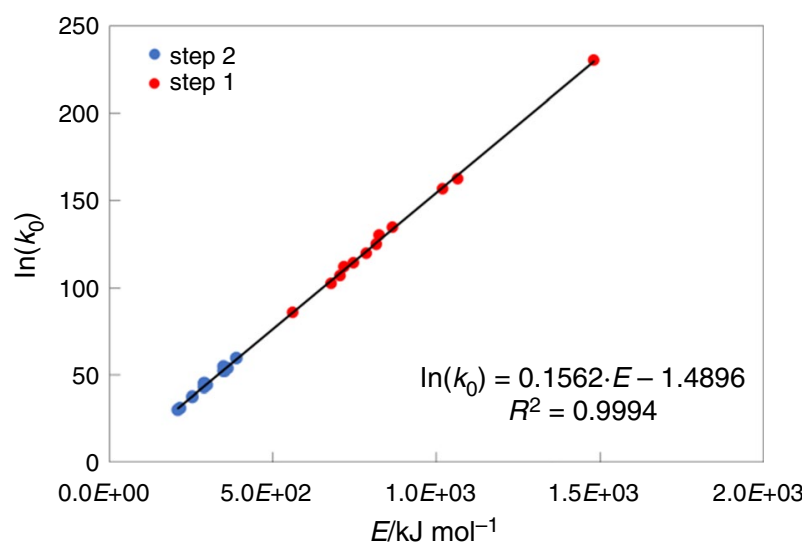

Fig. 12 The linear relation between frequency factor and energy of activation for the plasticization reaction

corresponding value of the frequency factor falls in a range of $1.2 \times 10^{13}-8.75 \times 10^{25}$. Both show the effect of volatile matter content expressed by metaplast content (Fig. 13).

The data fall into two distinguishable groups. The first is represented by low-volatile and related mesophase content $\left(M_{0}<0.21\right)$ and the second by high-volatile coals $\left(M_{0}>0.25\right)$. It seems that there is a different mechanism for fluidity phenomenon, which can be related to the different composition of the remaining volatiles due to much lower condensation and more side chains related to higher oxygen content. However, the higher the metaplast content is, the lower the value of the frequency factor and energy of activation.

A much better relation can be seen for the second step presented in Fig. 14a, b. It appears that in the solidification step, there is the same mechanism of the reaction, and metaplast content affects the reaction path in the same way.

Analysis of the data shows that frequency factor values are at least two orders of magnitude greater than for the first step. The same relates to the energy of activation, which takes values in the range $550-1050 \mathrm{~kJ} \mathrm{~mol}^{-1}$. In general, this may be expected because the reaction requires a higher temperature. The linear relation between frequency factor and energy of activation is almost perfect. 
The agreement between experimental measurements and model prediction is shown in Fig. 15a, b.

The reaction rate constants are presented for discussed cases in Fig. 16a, b.

It may be concluded that the reaction rate for the second step is faster than for the first one in both cases. This shows that the plasticization of coal takes longer than solidification, independently of coal rank. In the case of low-volatile coal, the same reaction rate can be achieved at a higher temperature.

\section{Kinetic analysis according to Model B}

In Fig. 17, a solution of the set of differential equations according to the described algorithm is presented. It shows three different runs chosen from a factorial template. The reaction of metaplast transformation into the plastic phase is represented by falling lines, and rising lines represent solid phase formation. The resulting parabolic lines are the plastic phase content.

The final solution must meet the criteria by stepwise correction of starting values of the assumed kinetic parameters. In this specific case, $M_{0}$ was equal to 0.141 , and calculated $P_{\max }=0.112$. In the case of high-volatile coal, $P_{\max }$ can be as high as $90 \%$ of $M_{0}$. This means that the solidification reaction starts before the maximum available amount of metaplast can be transformed into a plastic phase.

In this model, neither the frequency factor nor the activation energy shows a clear relationship with the content of
Fig. 13 The effect of metaplast content on frequency factor and energy of activation of the first step of the reaction

Fig. 14 The effect of metaplast content on frequency factor and energy of activation of the second step of the reaction
Fig. 15 The comparison of experimental data with calculated ones according to the developed model (a)

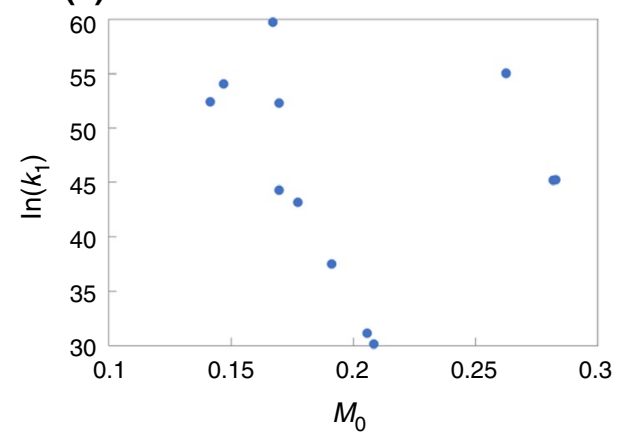

(a)
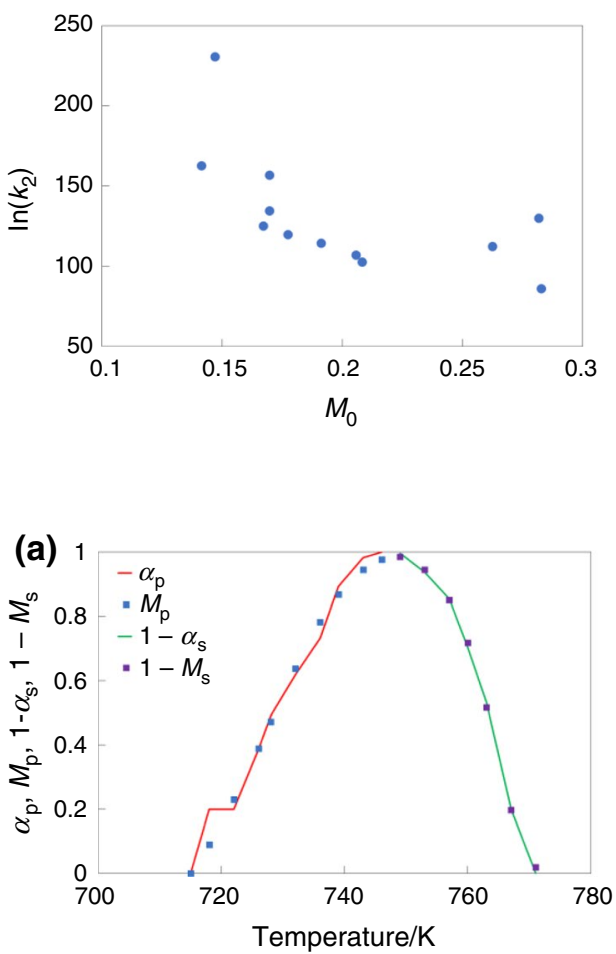

(b)

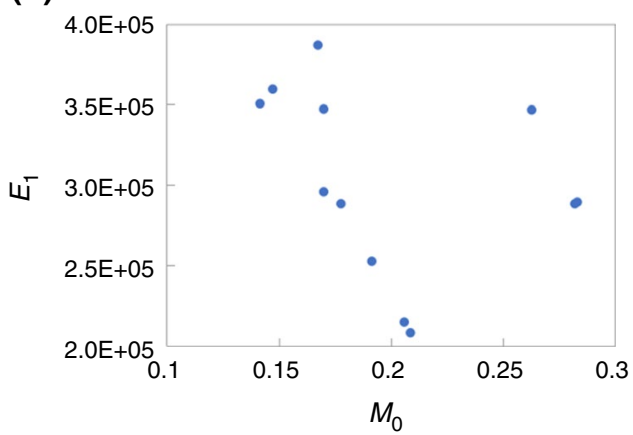

(b)
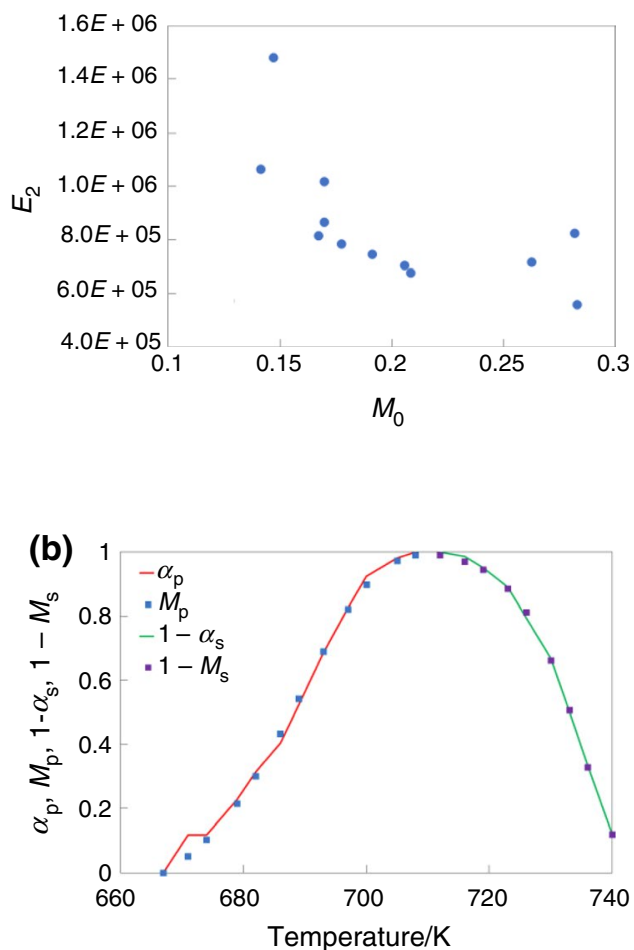
(a)

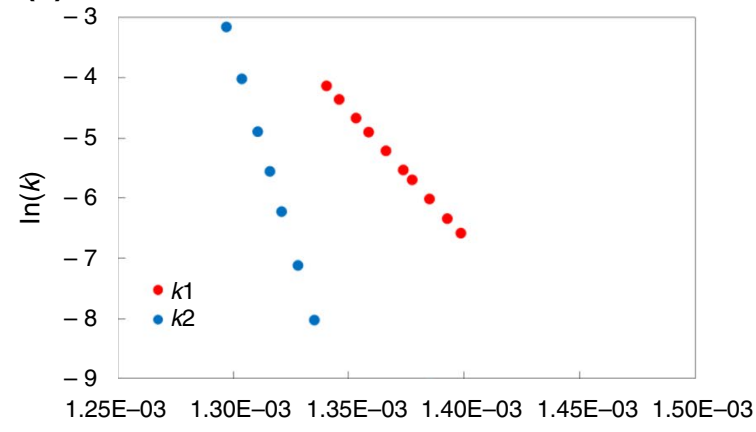

$1 / \mathrm{T}$ (b)

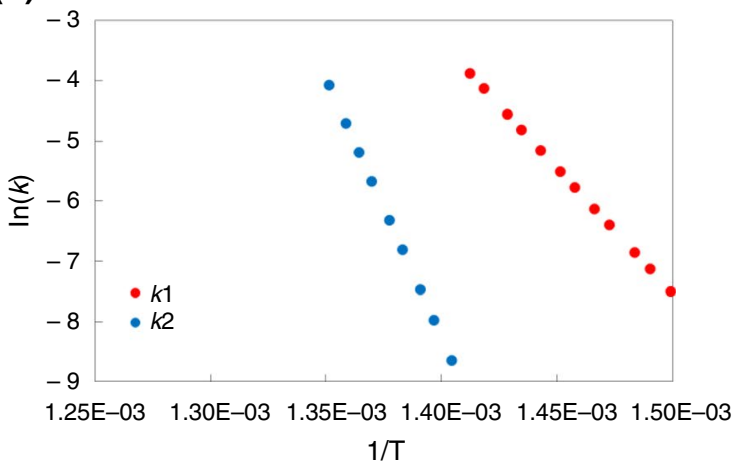

Fig. 16 The reaction rate constant versus reciprocal of temperature for low- and high-volatile coals

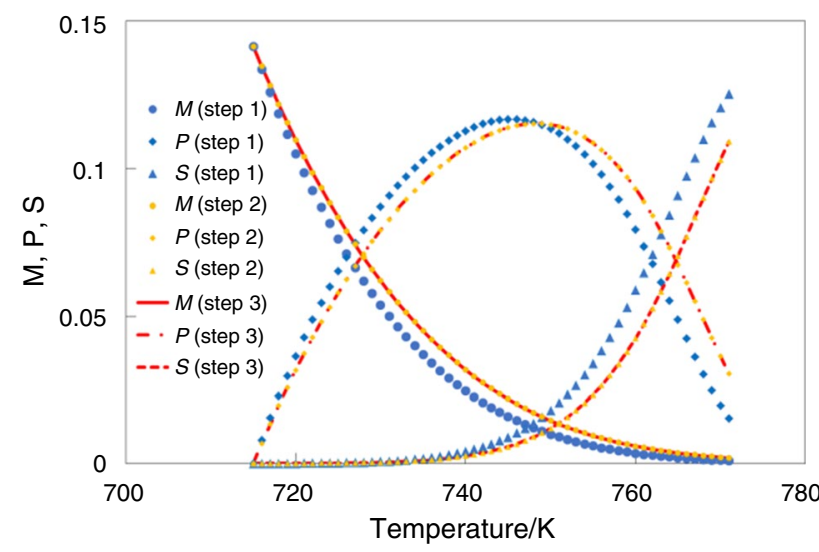

Fig. 17 Solutions of the set of differential equations for run numbers 1,8 and 16 according to the $2 \mathrm{k}$-factorial design (low-volatile coal)

metaplast. They show some correlation between themselves, but it is not linear, as was the case in Model A. The trend towards linearity can be observed for the second reaction.

Comparing the data obtained with Model B, it can be concluded that both kinetic parameters take smaller values than in the previous model. In particular, the value of the frequency factor is almost tenfold smaller than in Case
A for the first reaction. The activation energy in the first step ranges from $65-80 \mathrm{~kJ} \mathrm{~mol}^{-1}$ and, for the second, from $520-600 \mathrm{~kJ} \mathrm{~mol}^{-1}$. The last one is in the range of Model A findings.

However, given that the value of frequency factor and activation energy represents big numbers, the differences, particularly between the results obtained for the second reaction, are not so substantial. The smallest and largest values of activation energy differ by a maximum $4 \%$ from a mean $560 \mathrm{~kJ} \mathrm{~mol}^{-1}$.

In Fig. 19a, the results of the model solution in comparison with experimental data are presented. The respective residuals are shown in Fig. 19b. It is clearly demonstrated that the residuals for the solidification reaction are negligible, but this is not the case for the plastification step. In this step, complex reactions of devolatilization and regrouping of coal structure do not allow precise description by the model. In general, the peak temperature value was precisely computed, and the mean deviation does not exceed $5 \%$.

Considering the reaction rate, which is determined by the reaction rate constant, it can be concluded that they align very well, showing relatively good agreement (Fig. 20).
Fig. 18 Frequency factor versus energy of activation for both reactions
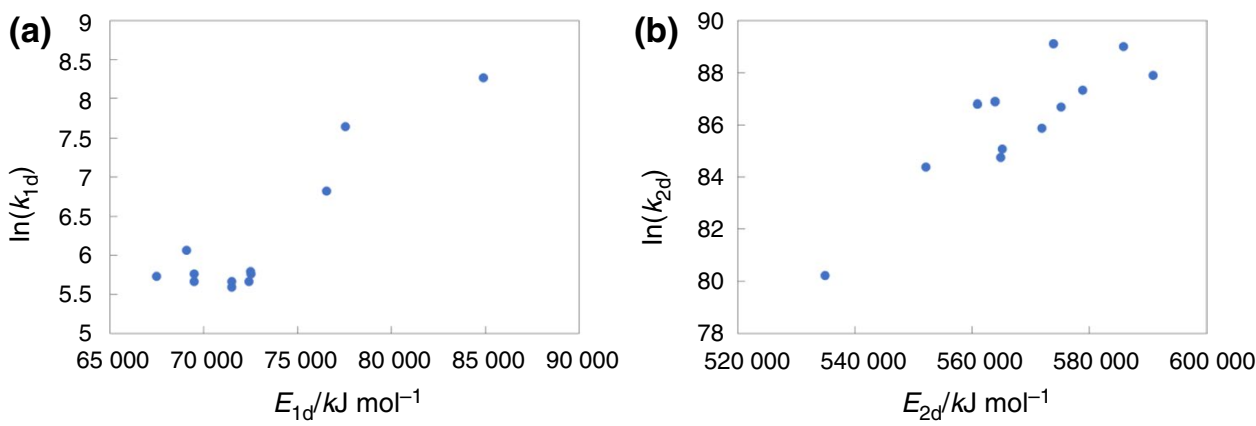
Fig. 19 The results of model computation and residuals of model prediction for coal $V^{\text {daf }}=26.05 \%$ (AU coal)

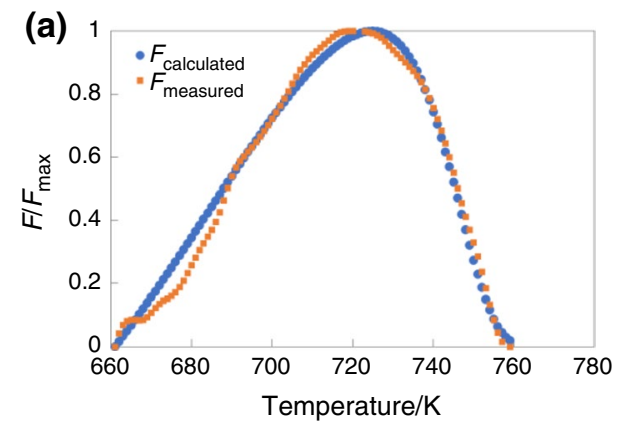

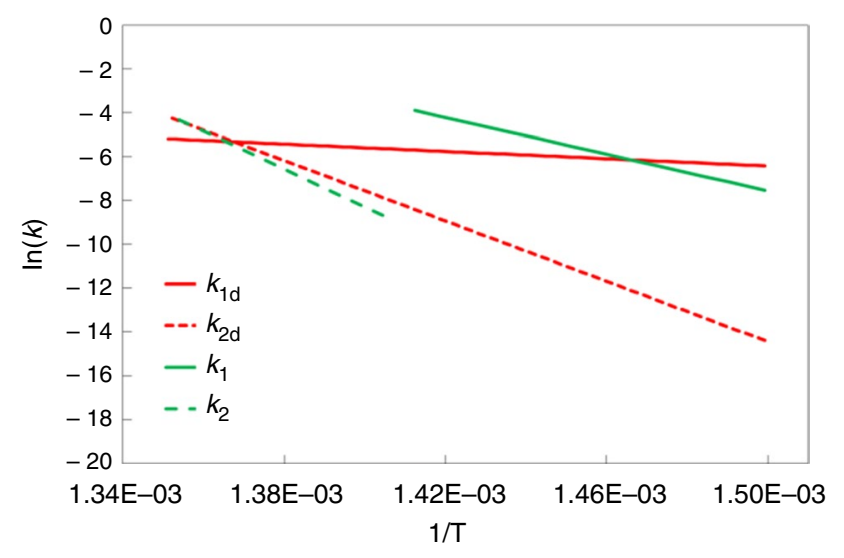

Fig. 20 Kinetic rate constants versus temperature for two reaction steps and two models

\section{Plastic phase viscosity}

Several factors contribute to the fluidity of coal in the plastic state, and this results in numerous correlations for viscosity calculations. One of the most comprehensive is the approach of Mooney [33], described in detail by Solomon et al. [34]. In this model, the volume fraction of the solid phase, $\Phi_{\mathrm{S}}$, was calculated from the model developed in this work. The other parameters were assumed as in the above-mentioned article. The results of viscosity changes with the temperature rise are shown in Fig. 21 for high and low volatile content coals. It can be noticed that the minimum of viscosity for high-volatile coal is lower than for low-volatile coal. In addition, the minimum is shifted towards higher temperature. In Fig. 22, the experimental results of Duffy et al. [35] are compared with model prediction, showing very good agreement considering the predicted range of minimal value of viscosity.

\section{Conclusions}

In the coal during the coking process, complex physicochemical changes take place. The most important phenomenon from the point of view of the formation of the coke structure is the formation and solidification of the plastic layer. The effect of this phenomenon together with the phenomenon of pyrolysis is the formation of an expansion pressure inside the coal charge, which in the form of coking pressure is transferred to the walls of the coking chamber. As a result of this work, a kinetic models of fluidity development of coking coals were elaborated. The models were validated with several coals of different origins and properties performing TGA and Gieseler tests. It allows predicting fluidity changes on the basis of volatile matter content.

In result, it is possible to calculate the formation and solidification rate of the plastic phase of any coal and its plasticity depending on the volatile matter content of the coal.
Fig. 21 Viscosity of plasticized coal versus temperature. $\mathbf{a}$ $V^{\text {daf }}=35.4 \%$ and $\mathbf{b} V^{\text {daf }}=20.9 \%$ (a)

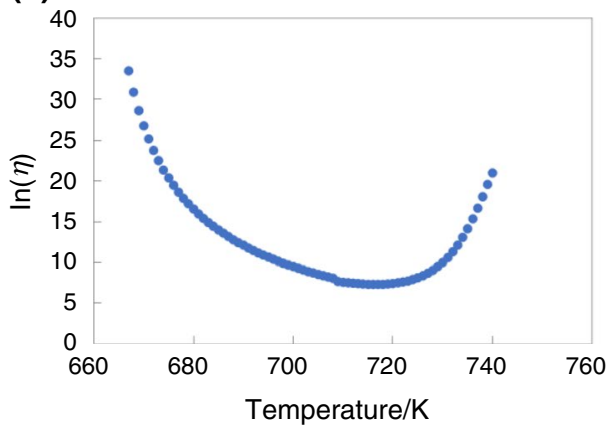

(b)

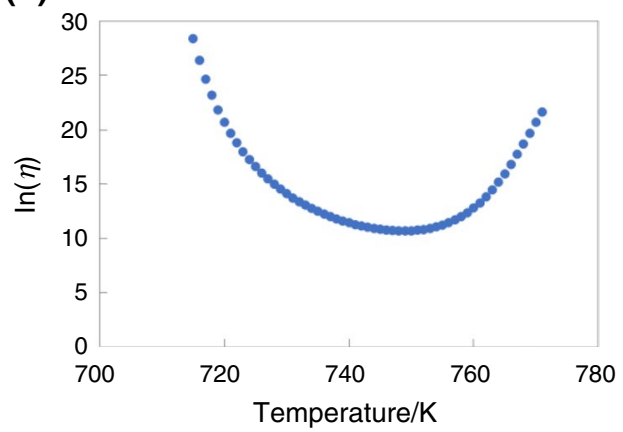




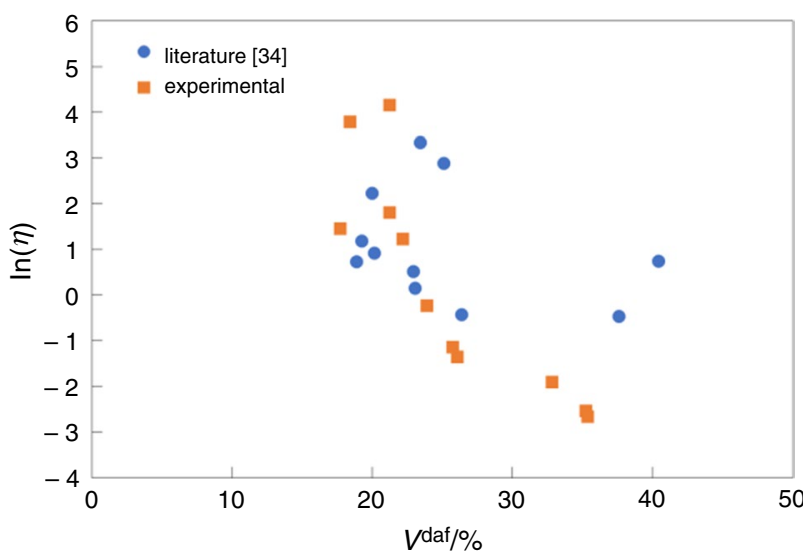

Fig. 22 Comparison of model and experimental data obtained by Duffy et al. [35]

Based on the experimental research presented in this paper, the following conclusions can be made:

- There exists in coal a substance called metaplast, which has the ability to plasticize.

- From the point of view of the mechanism, the process of coking coal pyrolysis can be described by means of subsequent metaplast plastification reaction and primary devolatilization, followed by solidification of metaplast in semi-coke/coke and secondary volatile component evolution.

- Two different mechanisms of fluidity development show that the final kinetic parameters align quite well. This means that the reaction models of plasticity development and solidification are based on solid considerations.

- Coal plasticity is related to the coal chemical structure, which determines the degree of plasticity of coal.

- The kinetic rate constants for Model A were in the range of $\ln \left(k_{1}\right)=-3.8 \div-7.5 \mathrm{~s}^{-1}$ and

- $\ln \left(k_{2}\right)=-4.1 \div-8.6 \mathrm{~s}^{-1}$ for plasticization and solidification, respectively. For Model B, the rate constant was very much alike in specific ranges of temperature. The results are in line with those presented by Gerjarusak [30] considering limited range of coal used and simplified assumption of theirs model.

Considering the presented scheme of coal behaviour while it is being heated, the following mechanisms were distinguished:

- The primary volatile matter is being released, and the remaining amount is equal to $0.8 \mathrm{~V}^{\mathrm{daf}}$ as metaplast turns into plastic phase starting at $t_{1}$ and ending at $t_{\max }$. This is followed by the solidification reaction. This can be considered the independent reactions model.
- The primary volatile matter is being released, and the remaining amount is equal to $0.8 \mathrm{~V}^{\mathrm{daf}}$ as metaplast turns into plastic phase starting at $t_{1}$ and at the same temperature starts competitive solidification reaction. This can be considered as reactions in the series model.

The developed models can be used for the prediction of the viscosity of the plastic state of coal, which in turn can be further used for the prediction of coal behaviour in a coking chamber, particularly coking (wall) pressure development as proposed by Duffy et al. [35].

Open Access This article is licensed under a Creative Commons Attribution 4.0 International License, which permits use, sharing, adaptation, distribution and reproduction in any medium or format, as long as you give appropriate credit to the original author(s) and the source, provide a link to the Creative Commons licence, and indicate if changes were made. The images or other third party material in this article are included in the article's Creative Commons licence, unless indicated otherwise in a credit line to the material. If material is not included in the article's Creative Commons licence and your intended use is not permitted by statutory regulation or exceeds the permitted use, you will need to obtain permission directly from the copyright holder. To view a copy of this licence, visit http://creativecommons.org/licenses/by/4.0/.

\section{References}

1. ISO 10329:2017 Coal—Determination of plastic properties—constant-torque Gieseler plastometer method. Retrieved from https:// www.iso.org/standard/70838.html

2. Merrick D. Mathematical models of the thermal decomposition of coal 1. The evolution of volatile matter. Fuel. 1983;62:534-9.

3. Donskoi E, McElwain DLS. Approximate modeling of coal pyrolysis. Fuel. 1999;78:825-35.

4. Arenillas A, Rubiera F, Pevida C, Pis JJ. A comparison of different methods for predicting coal devolatilisation kinetics. J Anal Appl Pyrolysis. 2001;58-59:685-701.

5. Mianowski A, Radko T. Thermokinetic analysis of coal pyrolysis process. J Therm Anal. 1995;43:247-59.

6. Anthony DB, Howard JB. Coal devolatilization and hydrogasification. AIChE J. 1976;22:625-56.

7. Solomon PR, Hamblen DG. Pyrolysis. In: Schlosberg RH, editor. Chemistry of coal conversion. New York: Plenum Press; 1985.

8. Juntgen H. Review of the kinetics of pyrolysis and hydropyrolysis in relation to the chemical constitution of coal. Fuel. 1984;63:731-7.

9. Buczynski R, Weber R, Kim R, Schwöppe P. One-dimensional model of heat-recovery, non-recovery coke ovens. Part II: coking bed sub-model. Fuel. 2016;181:1115-7.

10. Solomon PR, Best PE, Yu ZZ, Deshpande GV. A macromolecular network model for coal fluidity, symposium on coal characterization and geochemistry. Washington: ACS; 1989. p. 895-906.

11. Ouchi K, Itoh S, Makabe M, Itoh H. Pyridine extractable material from bituminous coal, its donor properties and its effect on plastic properties. Fuel. 1989;68:735-40.

12. Kidena K, Murata S, Nomura M. Studies on the chemical structural change during carbonization process. Energy Fuels. 1996;10:672-8.

13. Lloyd WG, Francis HE, Yewell Jr. MR, Kushida R, Sankur VD. A model for the isothermal plastometric behavior of coals. 
Preprints of papers presented at the symposium on catalytic reactions involving synthesis gas (II), vol. 25, Boston, ACS; 1980. pp. 128-137

14. Project Report. Smart coke plant satisfying requirements of the best available technology, WP 2.2, Institute for Chemical Processing of Coal, Zabrze; 2010 (unpublished, in Polish)

15. Karcz A. Cokemaking, Part I. Kraków: AGH University Scripts; 1991 (in Polish).

16. Jasieńko S. Chemistry and coal physics. Wrocław: Oficyna Wydawnicza Politechniki Wrocławskiej; 1995 (in Polish).

17. Leeder WR, Todoschuk T, Howey C, Giroux L, Ng KW, MacPhee T Predictive model for blending coking coals, Part II. US Coals. https://www.researchgate.net/publication/283101516_Predictive _model_for_blending_coking_coals_part_2_US_coals

18. Matsui T, Igawa K, Sorimachi K. Prediction of blended coal fluidity and lateral contraction of coal in coke ovens-technology for increasing the charging ratio of low quality coal in cokemaking. Kawasaki steel technical report, No. 38 (April 1998), Ironmaking Technology and Tubular Products Technology

19. Guangzhia Y, Tinga S, Qifeng Z, Yinping C, Weijia Z, Xincia $\mathrm{W}$, Jinga $\mathrm{L}$, Junhe $\mathrm{Y}$. An index of fluidity-temperature area for evaluating cohesiveness of coking coal by Gieseler fluidity characterization. Fuel Process Technol. 2018;177:1-5.

20. Guelton N. The prediction of the Gieseler characteristics of coal blends. Fuel. 2017;209:661-73.

21. Fernández AM, Barriocanal C, Alvarez R. The effect of additives on coking pressure and coke quality. Fuel. 2012;95:642-7.

22. Shmeltser EO, Lyalyuk VP, Sokolova VP, Miroshnichenko DV. The using of coal blends with an increased content of coals of the middle stage of metamorphism for the production of the blastfurnace coke. Message 1. Preparation of coal blends. Pet Coal. 2018;60(4):605-11.

23. Steel KM, Castro DM, Patrick JW, Snape CE. Use of rheometry and ${ }^{1} \mathrm{H}$ NMR spectroscopy for understanding the mechanisms behind the generation of coking pressure. Energy Fuels. 2004;185:1250-6.
24. Sciazko M, Karcz A, Winnicka G, Strugała A, Mertas B. Report on research Project No 4 T09C 037 25-model development of expansion pressure creation in plasticized coal grains bed, IChPW, Zabrze; 2006 (unpublished, in Polish)

25. Audibert E. The transient fusion of coal. Fuel. 1926;5:229.

26. van Krevelen DW, Schuyer J. Coal. Coal chemistry and its structure. Warszawa: PWN; 1959 (in Polish).

27. Świętosławski W. Physic-chemistry of hard coal and coking process. Warszawa: PWT; 1953 (in Polish).

28. Zieliński W. Cokemaking. Katowice: Śląsk; 1986 (in Polish).

29. Griaznov NS. Coal pyrolysis during coking process. Moskwa: Izd. Mietałłurgia; 1983.

30. Gerjarusak S, Peters WA, Howard JB. Coal plasticity at high heating rates and temperatures. Final technical progress report. Energy Laboratory and Department of Chemical Engineering, Massachusetts Institute of Technology; 1995

31. Loison R, Foch P, Boyer A. Coke quality and production. London: Butterworths; 1989.

32. Fernández AM, Barriocanal C, Díez MA, Alvarez R. Influence of additives of various origins on thermoplastic properties of coal. Fuel. 2009;88:2365-72.

33. Mooney MJ. The viscosity of a concentrated suspensions of spherical particles. J Colloid Sci. 1951;6:162-70.

34. Solomon PR, Best PE, Yu ZZ, Charpenay S. An empirical model for coal fluidity based on a macromolecular network pyrolysis model. Energy Fuels. 1992;6:143-54.

35. Duffy JJ, Mahoney MR, Steel KM. Influence of thermoplastic properties on coking pressure generation: part 1-a study of single coals of various rank. Fuel. 2010;89:1590-9.

Publisher's Note Springer Nature remains neutral with regard to jurisdictional claims in published maps and institutional affiliations. 